
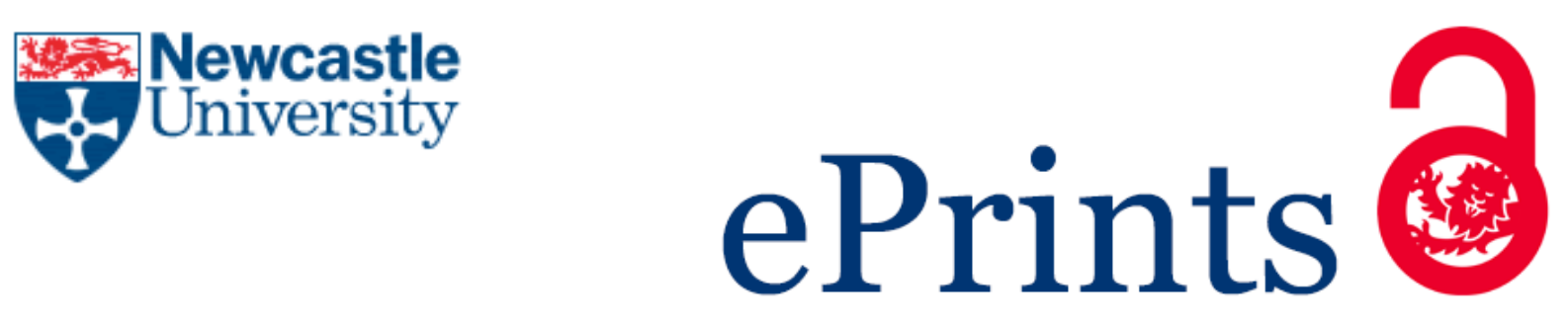

Bonilla R, Trejos A. (2017)

Marriage and Employment Participation with Wage Bargaining in Search

Equilibrium.

CESifo Working Paper Series, 6543

http://www.cesifo-group.de/ifoHome/publications/workingpapers/CESifoWP/CESifoWPdetails?wp id $=19333470$

Copyright:

(C) The authors.

Date deposited:

$20 / 07 / 2017$

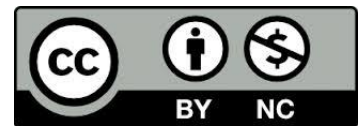

This work is licensed under a Creative Commons Attribution-NonCommercial 3.0 Unported License 


\title{
Marriage and Employment Participation with Wage Bargaining in Search Equilibrium.
}

\author{
Roberto Bonilla* \\ Newcastle University
}

\author{
Alberto Trejos \\ INCAE
}

\begin{abstract}
The empirical literature addressing links between the labor and the marriage markets is numerous and varied. Despite this, the theoretical (equilibrium) literature that explicitly links the two markets is less developed, particularly so with frictional markets. We build an equilibrium search model where married couples make joint decisions on home production and labor market participation. We then analyze the implications of our results for a frictional marriage market - allowing us to consider the interaction between both markets. A worker's bargaining position reflects their own productivity, and also the employment status and conditions of their spouse. We find that couples with very different productivities have different strategies regarding labor market participation. In symmetric couples, the partners behave symmetrically. Workers get better job offers when their spouses are employed, and in some equilibria a person may search for transitory jobs with the sole purpose of raising the long-term wages of their spouse. In some cases, firms unilaterally increase a worker's wage in order to reduce turnover, by ensuring that the spouse stays at home. Whether firms follow that strategy or not may be a matter of multiple equilibria, depending on parameter values. All this provides an additional explanation for wage and search behavior heterogeneity of similar workers and/or couples.

Keywords: labour market participation, wage formation, marriage market, linked frictional markets.

JEL Codes: D83,J12,J20,J31
\end{abstract}

\footnotetext{
*Corresponding author. email: roberto.bonilla@ncl.ac.uk. Telephone number: $+44(0) 1912081675$
} 


\section{Introduction}

The empirical literature addressing links between the labor and the marriage markets is numerous and varied. Despite this, the theoretical (equilibrium) literature that explicitly links the two markets is less developed, particularly so with frictional markets. To cite only a few empirical empirical contributions with results related to our equilibrium model, Bloemen and Stancanelli (2014) find that the wages of one spouse reduce the market labor supply -and increase the home production hours- of the other spouse. ${ }^{1}$ Korenman and Newmark (1991) is among the many pieces to document empirically a premium in wages for married men; others have elaborated that this relationship is stronger or more robust among married men with working wives. Among them, Jacobsen and Rayak (1996) show the data is consistent with the explanation that the wife's income allows the husband to search for better jobs. Song (2006) finds that the relationship is positive except when the wife is in management (which perhaps can be interpreted as her being in the labor market permanently rather than transitorily). Other papers show a positive effect of one spouse's earnings (or educational status) on the wages of the other spouse: see for instance Tiefenthaler (1994), Rosetti and Tanda (2000) or Huang (2009), for Brazilian, Italian and Chinese data respectively. All these empirical results are consistent with the findings in this paper. We believe that there is a shortage of theoretical (equilibrium) literature addressing the link between these two markets, and our aim is to contribute towards filling that void.

We develop an equilibrium search model where agents enter the economy in married couples, with both partners unemployed, and individuals have a decision to allocate their efforts among employment and home production. We focus on parameters such that the complementarity between wage income and the value of home production is so high that every couple will find optimal to always have someone at home ${ }^{2}$. We assume wages are

\footnotetext{
${ }^{1}$ In this case, the effects are different in nature between men and women. In particular: "The wage of the father has a significantly negative effect on the mother's market hours, while her wage rate has a significantly positive effect on his house work hours." We do not allow for gender differences in our model, which prevents us from capturing these nuances.

${ }^{2}$ If we think of "home production" as chores, a higher income allows the couple, for instance, to acquire the appliances and other equipments that make those chores to be more pleasant or more efficient. If we think of home production as leisure, a higher income buys things that make it more fun.

In Bonilla and Trejos (2015) we look at other parameters in which the choice about
} 
determined by bargaining between firms and potential employees, and find several interesting results: First, because the bargaining position of a worker is stronger when their spouse has a higher income, married people's income is correlated in that the better paid you are, the higher pay your spouse can bargain. This generates a correlation in spouse earnings that does not arise directly from, but affects, the degree of assortative.. Second, we find equilibria where the spouse with lower earning potential transitorily goes to the job market, just to improve with their salary the bargaining power of their partner; or refrains at all from labor market participation. This makes family income inequality larger than individual income inequality. Third, for some parameter values, it may be an equilibrium outcome that the more productive spouse stays at home and the less productive one remains the sole bread winner, obviously an inefficient arrangement. Fourth, for fairly productive couples where the productivities are not too apart (but also not too similar), we find that employers prefer to unilaterally increase the wage of the more productive spouse in order to reduce turnover by ensuring that the spouse stays at home. Throughout, we call this a "bribe". This compresses the upper part of the wage distribution relative to the productivity distribution as some relatively productive workers see their wage increased. Sixth, for some couples there may be multiple equilibrium wages and job search strategies. The multiple equilibria results from the feedback between a unilateral wage increase by the firm and the effects of this on individual wages: if firms follow this strategy in equilibrium, this increases the worker's bargaining position vis-a-vis an individual firm. This makes the bribe required lower relative to the otherwise agreed wage, and thus more likely to be optimal.

We derive some interesting results related to the relative productivities of partners. First, in our model, productive equality among partners is inefficient: with two high productivity workers within a marriage and one of them staying at home, this as waste of either's high productivity (also, not necessarily the least productive's). Second, the degree of within marriage heterogeneity affects both the labor-search behavior of individuals and the wages that they can bargain. Hence, when the economy consists of more unequal marriages, there is an increase in heterogeneity both in the search behavior and wages of seemingly equal agents and/or couples. This is result is strengthened by the fact that we find multiple equilibria in the labor

whether to be a two-income family is relevant. We simplify matters here in order to focus on the wage and bargaining problem. 
market for some types of couples, which provides an additional source of heterogeneity in search and wages.

These results are related to class formation -as in the seminal work by Burdett and Coles (1997)-, and more generally to assortative matching. Our modeling of the labor market has interesting implications for the modeling of, and the consequences from, a marriage market. This because some of the outcomes are in stark contrast with the assumptions in Burdett and Coles (1997). We find that, for newly born marriages: a) The utility within marriage depends on own productivity in addition to the partner's productivity, b) Utility within marriage is not monotonic on the partner's productivity, and c) Agents differ on the ranking between any two potential spouses. Both $b$ ) and $c$ ) stem from the "bribe" discussed above. We discuss the implications of this for marriage formation, and in turn the implications of this for our results in the labor market. Our conclusion is that the effects of an increase in the rate at which potential spouses are found depend on the rate at which jobs are found. For low job arrival rates, if it is easy to find potential partners this tends to favor assortative matching, thus making relevant the inefficiency found in marriages between highly productive partners. If it is difficult to find potential spouses this weakens assortative matching and generates different types of couples in equilibrium, thus magnifying the prevalent heterogeneity in wages and search behavior. These results are partially reversed when job arrival rates are high.

This theoretical work relates to Violante et al. (2012), which characterizes the reservation wage strategies of married individuals who face an exogenous distribution of wages within a frictional labor market, to obtain results related to link between marital status and labor market participation. In Bonilla and Trejos (2015), we develop a very similar model without wage bargaining to study the equilibrium combinations of labor participation strategy that may emerge, and their efficiency properties. Bonilla and Kiraly (2013) and Bonilla et al. (2015) derive a marriage wage premium as the consequence of the interaction between the labor and marriage markets.

The analysis of the issue with non-frictional markets is more extensive. A deep treatment can be found in Grossbard (2015), which is based on the pioneering work by Becker. The starting motivation there seems to be similar to ours, in that it is natural to analyze the feedback between decisions in the marriage and labor markets, and parameters and events in one of them will affect decisions in the other one. Some of our assumptions are more in line with traditional theoretical search literature than to the above literature.. 
Mainly, we assume utility is linear in income and value of home production, and we assume that labor market participation is a binary decision. We believe expanding on these assumptions is a fruitful avenue for further work.

We describe the environment in Section 2, and derive and analyze the equilibrium in Section 3. In Section 4 we discuss our results, and we conclude in Section 5.

\section{The environment}

Time is continuous and continues forever. The population is a continuum of measure of infinitely lived agents arranged in pairs, who discount future consumption at rate $r$. Each agent is endowed at birth by an observable productivity $p \in[p, \bar{p}]$, taken from the distribution function $F(p)$.

Agents enter the economy married, with both spouses unemployed. An unemployed worker can search for potential employers at a search $\operatorname{cost} \varepsilon$; we assume $\varepsilon>0$ but look at the limit case where $\varepsilon \rightarrow 0$. Firms will be found through Poisson process, with arrival rate $\lambda$. Employed workers cannot search. All employers (firms) are identical and able to generate costlessly as many vacancies as they want, and only workers matched with a firm are able to produce. Hence, as long as a job is profitable the firm does not need to terminate it to make room for others, and its interaction with one potential employee is not affected by quantity or qualities of its other current or potential workers. Upon a match, firm and worker enter a bargaining game to decide the wages, with full information regarding the productivity and working history of the worker and the worker's spouse. Both partners in a couple share all aspects of their life, so they enjoy the same (joint) utility from their joint income and joint home production ${ }^{3}$. In any given couple, we use $H$ to refer to the most productive partner and $L$ to refer to the least productive partner.

\footnotetext{
${ }^{3}$ Notice there is no mention of gender in this formulation. This can be interpreted in two ways. One, simply, that each being of the other's preferred gender is part of what we call "compatibility". Another is that everybody can match with everybody else. The formulation and equilibria are equivalent, on the other hand, to assuming that there are two genders, the distribution of all relevant parameters is equal among both, and we focus on symmetric equilibria. In any event, for exposition purposes we may assume at times a gender language (he and she, husband and wife, etc.).
} 
The bargaining game that determines wages is as follows: Upon meeting, the firm offers a wage, which the worker may accept of reject. If the worker rejects it, then after a small wait of duration $\Delta$ either party has a probability $1 / 2$ of making the second (and final) offer. If that one is also rejected, the pair breaks off. We are interested of course on the limit case as $\Delta \rightarrow$ $0 .{ }^{4}$ If either offer is accepted, that contract is binding. The only way to alter the commitment is by quitting the job (there is no within-the-match renegotiation). For now, we assume that any worker who quits a job must also leave the labor market forever; we discuss the implications of relaxing this assumption in Section 4.

Not only income purchases goods that can be enjoyed directly, but the value of home production increases with income as well (that, for instance, enables to acquire household goods that complement home work). To obtain home production, however, requires at least one spouse to stay at home, and in absolute terms all agents are equally productive at home. We denote $\alpha$ the marginal effect that income has as an enhancer of home production, which is then $h+\alpha w$. For starters, we will assume $\alpha=1$, which implies that joint utility is $U=w_{1}+w_{2}$ if both are employed at those wages, $U=2 w+h$ when one spouse is earning $w$ and the other one is at home, and $U=h$ if both are jobless. We discuss the implications of relaxing this assumption to $\alpha<1$ in Section 4 .

\section{Equilibrium}

\subsection{The labor market}

Because $\alpha=1$, we know that at any given time at most one spouse in each couple will be employed:

Lemma 1 Given $\alpha=1, a)$ it is never optimal for both spouses to be employed and keep their jobs simultaneously; b) if one spouse is employed, the other spouse would only search for a new job if in equilibrium she would get a higher wage; $c)$ if $H$ is employed at a wage $w \geq p_{L}$, then $L$ is off the labor

\footnotetext{
${ }^{4}$ This is the bargaining game used in Bonilla and Burdett (2010). As there, this departure from the more standard Nash bargaining option is justified because in this environment the choice set may not be convex, and hence the axiomatic Nash solution may not exist.
} 
market, while there is no wage -in equilibrium- payable to $L$ such that $H$ would leave the labor market.

Proof. a) Assume for a moment both spouses are working, and let the least paid spouse (not necessarily $H$, because $L$ may have been in a stronger bargaining position than $H$ when their wages got determined) make $w$ and the best paid one make $W>w$. While keeping both, they enjoy a flow utility of $W+w$, (there are no exogenous breakups, and no search on-thejob, to break that flow), while the moment the worker least paid quits (and thus leaves the labor market) the couple enjoy a flow (also uninterrupted) of $2 W+h>W+w$. b) Since search is costly, one only looks for a job if expecting that one may take it. c) Independent of the outside options and bargaining position, the highest wage that $L$ can be offered is $p_{L}$. By virtue of the previous point, such wage would not be acceptable if $H$ is already making $w \geq p_{L}$. The same does not apply in the other direction, since paying $w \geq p_{H}$ to $L$ leaves the employer with negative profit.

In principle, a newlywed couple may decide that both spouses search in the labor market from the outset. On the other hand, they may also choose that initially only of one of them searches, delaying the expected arrival of their first income (since two searching will find on average before only one searching), but securing the order in which their jobs are going to come. This could happen because, with bargaining, an agent with a better paid spouse has stronger outside options, and gets offered a higher wage. Then, the winning strategy for a couple that desires $H$ to be the long-term breadwinner of the family could be to have $L$ look a job first, to ensure that $H^{\prime}$ 's wage is higher. While in the end we will prove that this does not happen in equilibrium and both spouses search from the outset, to prove it we need to allow for these possibilities. We will call $\phi_{0}$ the probability that $H$ searches when both partners could and neither is working, and $\phi_{1}$ the analogous probability for $L$. It is straightforward to show that when $L$ gets a job before $H$ (whether both or only $L$ were searching), it is always optimal for $H$ to search. We will define $\phi_{2}$ as the probability that $L$ searches for a job given that $H$ finds a job first

To complete the notation: if spouse $k \in\{H, L\}$ is the first one to find a job, we denote $w_{k}^{1}$ their resulting wage. If, on the contrary, her partner is already employed at salary $w$ when $k$ finds a job, then the wage will be $w_{k}^{2}(w)$. The value function of the state where both agents are unemployed and eligible to search is denoted $V_{00}$. The value of having $H$ employed and 
earning $w$ while $L$ is not working is denoted $V_{10}$ if $L$ is able to search, and $\bar{V}_{H}$ if $L$ has already quit a job and been forced to leave the labor market. Analogously, the state where $L$ working and earning $w$ while $H$ searching has value $V_{01}$, and the state where $H$ has left the labor market is $\bar{V}_{L}$. We will not need to use $V_{11}$ (since it is never optimal for both spouses to work at the same time, given $\alpha=1, h>0$ ).

The Bellman equations write now as

$$
\begin{aligned}
r V_{00} & =h+\lambda \phi_{0}\left[V_{10}\left(w_{H}^{1}\right)-V_{00}\right]+\lambda \phi_{1}\left[V_{01}\left(w_{L}^{1}\right)-V_{00}\right] \\
r V_{01}\left(w_{L}^{1}\right) & =2 w_{L}^{1}+h+\lambda\left[\bar{V}_{H}\left(w_{H}^{2}\left(w_{L}^{1}\right)\right)-V_{01}\left(w_{L}^{1}\right)\right] \\
r V_{10}\left(w_{H}^{1}\right) & =2 w_{H}^{1}+h+\lambda \phi_{2}\left[\bar{V}_{L}\left(w_{L}^{2}\left(w_{H}^{1}\right)\right)-V_{10}\left(w_{H}^{1}\right)\right] \\
r \bar{V}_{H}\left(w_{H}^{2}\right) & =2 w_{H}^{2}+h \\
r \bar{V}_{L}\left(w_{L}^{2}\right) & =2 w_{L}^{2}+h
\end{aligned}
$$

where the probabilities $\phi_{i}$ describe the optimal search strategies, by virtue of Lemma 1, and must satisfy the incentive compatibility conditions

$$
\begin{aligned}
& \phi_{0}=\left\{\begin{array}{lc}
1 & V_{10}\left(w_{H}^{1}\right)>V_{00} \\
0 & \text { otherwise }
\end{array}\right. \\
& \phi_{1}=\left\{\begin{array}{cc}
1 & V_{01}\left(w_{L}^{1}\right)>V_{00} \\
0 & \text { otherwise }
\end{array}\right. \\
& \phi_{2}=\left\{\begin{array}{cc}
1 & w_{H}^{1}<p_{L} \\
0 & \text { otherwise }
\end{array}\right.
\end{aligned}
$$

Recall that when bargaining for a wage, the firm always makes the first offer, knowing that if rejected then, after a wait $\Delta \rightarrow 0$, the definitive counteroffer will be made by either party with probability $1 / 2$. Normally, the firm would offer the wage that makes the worker indifferent between accepting it, or rejecting it and getting a 50-50 chance of making the second and final offer (assuming that if the firm makes the second offer, it would extract all the surplus). For instance, when the firm is bargaining with $H$ over $w_{H}^{2}$, because $L$ is already employed and earning $w_{L}^{1}$ with value $V_{01}$, the equilibrium offer $w_{H}^{2}$ is defined by

$$
\bar{V}_{H}\left(w_{H}^{2}\right)-V_{01}\left(w_{L}^{1}\right)=\frac{1}{2}\left[\bar{V}_{H}\left(p_{H}\right)-V_{01}\left(w_{L}^{1}\right)\right]
$$

The left hand side represents the gain from the worker of accepting that offer: it will earn $w_{H}^{2}$ forever, while her spouse $L$ stays at home therefore securing 
a permanent flow utility of $2 w_{H}^{2}+h$, while leaving behind the value $V_{01}$. The right hand side represents the gain for the worker of rejecting the offer: it will get cleaned out for no surplus in the event, with probability $1 / 2$, that the firm makes the second offer, yet it will get, also with probability $1 / 2$, the entire surplus, by being paid perpetually a wage $p_{H}$. In equilibrium the firm makes the offer that barely gets accepted, thus equating the left and right hand sides. A similar logic applies for the determination of $w_{L}^{1}$ and $w_{L}^{2}$, which delivers

$$
\begin{aligned}
V_{01}\left(w_{L}^{1}\right)-V_{00} & =\frac{1}{2}\left[V_{01}\left(p_{L}\right)-V_{00}\right] \\
\bar{V}_{L}\left(w_{L}^{2}\right)-V_{10}\left(w_{H}^{1}\right) & =\frac{1}{2}\left[\bar{V}_{L}\left(p_{L}\right)-V_{10}\left(w_{H}^{1}\right)\right]
\end{aligned}
$$

The analysis of the bargaining to determine $w_{H}^{1}$ is much more complicated. One could think that the firm offers a wage $w$ that emerges from an equation analogous to (4), but this would be wrong: the right hand side of (4) reflects the expected payoff for the $L$ of rejecting the firm's first offer, and getting to make the second. In that case, $L$ would demand to be paid $p_{L}$, in the knowledge that $H$ continues searching (so the continuation value is $\left.V_{01}\left(p_{L}\right)\right)$. If the same thing happened when $H$ is bargaining, $H$ knows that upon demanding $p_{H}$ in the second round, $L$ would not continue searching, because no firm would want to pay it more than $p_{H}$, so the continuation value is not $V_{10}\left(p_{H}\right)$ but rather $\bar{V}_{H}\left(p_{H}\right)$. Therefore, the minium acceptable wage for the firm to offer is $w^{*}$, satisfying

$$
V_{10}\left(w^{*}\right)-V_{00}=\frac{1}{2}\left[\frac{2 p_{H}+h}{r}-V_{00}\right]
$$

and, if $w^{*} \geq p_{L}$, this is what will happen. Please note $w^{*} \geq p_{L}$ is only consistent with using $\phi_{2}=0$ in $V_{10}\left(w^{*}\right)$. In the event $w^{*}<p_{L}$ (consistent only with $\phi_{2}=1$ in $\left.V_{10}\left(w^{*}\right)\right)$ then there are two possibilities. The first one is is for the firm to offer wage $w^{*}$, in which case she knows that the worker's partner (the $L$ ) will search on the job, eventually find a better job, inducing $H$ to quit. In this case, the firm's expected lifetime discounted profit from offering $w^{*}$ is $\frac{p_{H}-w^{*}}{r+\lambda}$. The second option is for the firm to pay $p_{L}:$ she would make a lower flow profit, but the flow would continue forever, and then the discounted lifetime profit would be $\frac{p_{H}-p_{L}}{r}$. We colloquially refer to this last choice as "bribing" $L$, as the firm in a way is offering an extra payment to $H$, 
in order to induce $L$ to stay at home. ${ }^{5}$ Clearly, the firm would prefer to bribe and pay $p_{L}$, instead of $w^{*}<p_{L}$, if and only if $\frac{p_{H}-p_{L}}{r}>\frac{p_{H}-w^{*}}{r+\lambda}$, or $g\left(w^{*}\right) \geq 0$, where

$$
g\left(w^{*}\right) \equiv \frac{\lambda p_{H}+w^{*} r-(r+\lambda) p_{L}}{r(r+\lambda)}
$$

There is one other complication: in the event bribing did not happen in the first offer of the bargaining game, we need to consider whether it is reasonable to expect the firm would bribe if it got to make a second offer. This second offer would never be observed along the equilibrium path, but its value affects the wages one does observe. To discuss this, it is useful to define two alternative values for $w_{H}^{1}$, called $\bar{w}$ and $\widetilde{w}$, as follows: $\bar{w}$ is the minimum wage that $H$ is willing to accept in the second round of the bargaining game (notice that clearly $\bar{w}<w^{*}$ ), while $\widetilde{w}$ is the lowest wage $H$ is willing to accept in the first round, given an expectation that the firm would make a bribing offer of $p_{L}$ in the second round (and clearly $\widetilde{w}>p_{L}$ ). These values are implicitly defined by

$$
\begin{aligned}
V_{10}(\bar{w}) & =V_{00} \\
V_{10}(\widetilde{w})-V_{00} & =\frac{1}{2}\left[\frac{2 p_{H}+h}{r}-V_{00}\right]+\frac{1}{2}\left[\frac{2 p_{L}+h}{r}-V_{00}\right]
\end{aligned}
$$

Which of these values of $w_{H}^{1}$ will be offered by the firm in the first iteration of the bargaining game, and always accepted, in equilibrium? From the previous analysis, it follows that

$$
w_{H}^{1}= \begin{cases}p_{L} & \Longleftrightarrow g(\bar{w}) \leq 0, w^{*}<p_{L} \text { and } g\left(w^{*}\right)>0 \\
\widetilde{w} & \Longleftrightarrow \bar{w}<p_{L} \text { and } g(\bar{w})>0 \\
w^{*} & \Longleftrightarrow \begin{array}{l}
\text { i) } w^{*}<p_{L} \text { and } g\left(w^{*}\right) \leq 0 \text { or } \\
\end{array} \quad \text { ii) } p_{L} \in\left[\bar{w}, w^{*}\right] \text { and } g(\bar{w}) \leq 0 \text { or } \\
& \text { iii) } \bar{w} \geq p_{L}\end{cases}
$$

\footnotetext{
${ }^{5}$ Notice that this dilemma only arises when the firm is bargaining with $H$ and $L$ is still eligible to search, that is, over $w_{H}^{1}$. By Lemma 1, if the situation was reversed, and the negotiation involved $L$ instead of $H$, the firm would know that anything that is profitable to offer $L$ will be topped eventually by $H^{\prime}$ 's eventual employer, so there is no way of avoiding turnover. And in the event where firm and worker bargain while the spouse is employed, -that is, when determining $w_{H}^{2}$ or $w_{L}^{2}$ - the firm would know that bribing is not necessary, as the couple has no outside search option after the employed spouse quits and leaves the labor market.
} 
The condition in the first line implies that even though firms would not bribe if they got to make a second offer, or $g(\bar{w}) \leq 0$, they still prefer to bribe in the first $\left(g(\bar{w}) \leq 0, w^{*}<p_{L}\right)$. The condition in the second line implies that the firm would prefer to bribe in the event it reached the second stage - and hence a bribe on the first stage is not necessary. The condition in the first subcase of the third line means that it is not profitable for the firm to bribe in either stage (It is easy to show that if it is not profitable to bribe in the first stage assuming no bribe in the second stage, then it is not profitable to bribe in the second stage.). The condition in the second subcase means bribe is not necessary in the first stage even if there is no bribe in the last stage. The condition in the last case means that bribe is not necessary in the second stage because there is bribe in the last stage. Since $\widetilde{w}>p_{L}$ and $w^{*}>\bar{w}$, the conditions in (8) describe all the possibilities.

Definition 1 An equilibrium is a combination $V=\left\{V_{00}, V_{10}, V_{01}, \bar{V}_{H}, \bar{V}_{L}\right\}$, $\phi=\left\{\phi_{0}, \phi_{1}, \phi_{2}\right\}$ and $w=\left\{w_{L}^{1}, w_{H}^{1}, w_{L}^{2}\left(w_{H}^{1}\right), w_{H}^{2}\left(w_{L}^{1}\right)\right\}$ that satisfy (1)-(6) and (8), given (7).

The set of potential equilibria is made much simpler by the following result, that implies both spouses enter the labor market the moment they marry, when they are both unemployed:

Lemma 2 In all equilibria, $\phi_{0}=\phi_{1}=1$

Proof. We consider the different other possibilities one by one, to verify they are not best strategies.

1. Obviously, $\phi_{0}=\phi_{1}=0$ could never be part of a best search strategy, because a deviation where either agent searches would increase expected income at no cost, as $2 w+h>h$ always.

2. The choices $\phi_{0}=1, \phi_{1}=0$ cannot be optimal. A one-time deviation to $\phi_{1}=1$ does not change the moment when $H$ will find a job; meanwhile, with probability $1 / 2$ it has no effect on the outcome, and with probability $1 / 2$ it increases flow payoff for a fraction of the time before that moment when $H$ finds a job from $h$ to $h+2 w_{L}^{1}>h$, and flow payoff after that moment from $w_{H}^{1}$ to $w_{H}^{2}>w_{H}^{1}$. Both changes are strictly positive so this one-time deviation from equilibrium represents an improvement, which means that $\phi_{0}=1, \phi_{1}=0$ are not an optimal choice. 
3. To verify that the choices $\phi_{0}=0, \phi_{1}=1$ cannot be optimal, one needs to check several cases, depending on whether, off the equilibrium path if there was a deviation to $\phi_{0}=1$, one would observe a) firms do not bribe, yet $w_{H}^{1}>p_{L}$, so $\phi_{2}=0$; or b) firms do not bribe, while $w_{H}^{1}<p_{L}$, so $\phi_{2}=1$; or c) firms bribe so $\phi_{2}=0, w_{H}^{1}=p_{L}$. If, down all of those paths, it turns out that $V_{10}<V_{00}$, that would verify that the one-time deviation to $\phi_{0}=1$ would not pay off, and thus that equilibria with $\phi_{0}=0, \phi_{1}=1$ exists. However, it is straightforward to demonstrate that:

(a) Assuming $w_{H}^{1}=\widetilde{w}$ one can verify that $V_{10}-V_{00}=\frac{2\left(2 r p_{L}+\lambda p_{H}\right)}{(2 r+\lambda)^{2}}>0$, so a one shot deviation to $\phi_{1}=1$ is always payoff-improving.

(b) The previous statement is true independently of whether $\widetilde{w} \geq p_{L}$ and $\phi_{2}=0$, or $\widetilde{w}<p_{L}$ and $\phi_{2}=1$.

(c) Consider now the case where there is bribing, and agents expect off the equilibrium path $w_{H}^{1}=p_{L}, \phi_{2}=0$. Then, for $V_{10}<$ $V_{00}, p_{L}<\frac{\lambda^{2} p_{H}}{4 r^{2}+2 \lambda r+\lambda^{2}}$, and for $p_{L}>\widetilde{w}$ one needs $p_{L}>\frac{\left(\lambda^{2}+\lambda r\right) p_{H}}{2 r^{2}+2 \lambda r+\lambda^{2}}$. Obviously, both inequalities cannot be true at the same time, and therefore a couple that expected bribing would prefer $H$ to enter the market immediately, rather than wait for $L$ to find a job before $H$ searches.

On the basis of the lemma and the analysis so far, a search equilibrium is characterized by the values of $\phi_{2}$ and $w_{H}^{1}$. We can infer that there are four qualitatively different types of outcomes that may emerge as equilibrium in this model. The first one (we shall call it Type A) is the situation where firms do not bribe (pay $w_{H}^{1}=w^{*}<p_{L}$ ) and $L$ searches when $H$ finds a job first $\left(\phi_{2}=1\right)$. In the other three, $L$ never searches if $H$ finds a job first, either because the firm bribes in the first offer (Type B, $w_{H}^{1}=p_{L}$ ), because the firm would pay a bribe in second offer and then pay even more in the first (Type $\left.\mathrm{C}, w_{H}^{1}=\tilde{w}\right)$, or because the wage is so naturally high that bribing is not necessary (Type D, $w_{H}^{1}=w^{*}>p_{L}$ ). Notice that wages in Equilibria A and $\mathrm{D}$ are in both cases given by the unconstrained outcome of the bargaining process: $w_{H}^{1}=w^{*}$, but for opposite reasons. In the former, because $L$ is so productive that bribing is too expensive; in the latter, because it is so unproductive that bribing is not necessary. 
Using this characterization we describe the existence conditions in the following proposition:

Proposition 1 There is always at least one pure strategy equilibrium. There exist functions $x_{i}<1$ such that:

i) A type $A$ outcome is an equilibrium if $x_{5}<\frac{p_{L}}{p_{H}}<1$

ii) A type $B$ outcome is an equilibrium if $\max \left\{x_{1}, x_{4}\right\}<\frac{p_{L}}{p_{H}}<x_{6}$.

iii) A type $C$ outcome is an equilibrium if $x_{0}<\frac{p_{L}}{p_{H}}<x_{3}$.

iv) A type $D$ outcome is an equilibrium if either $x_{2}<\frac{p_{L}}{p_{H}}<x_{4}$, or $\frac{p_{L}}{p_{H}}<x_{0}$.

Proof. Consider first the existence of an equilibrium where $\phi_{2}=1, w_{H}^{1}=w^{*}$; solve (1), (3) - (6) to obtain candidate values for $V_{H L}, w_{k}^{i}, \bar{w}, \widetilde{w}$ and $w^{*}$. The conditions (2) and (8) are $p_{L}>w^{*}, g(\bar{w}) \leq 0, V_{00}<\min \left\{V_{01}, V_{10}\right\}$ and $g\left(w^{*}\right) \leq 0$, which in turn translate into $p_{L} / p_{H} \geq \frac{2(r+\lambda)^{2}}{4 r^{2}+5 \lambda r+2 \lambda^{2}}, p_{L} / p_{H} \geq$ $\frac{3 \lambda(r+\lambda)}{2 r^{2}+4 \lambda r+3 \lambda^{2}}$ and $p_{L} / p_{H} \geq \frac{2(r+\lambda)(r+3 \lambda)}{4 r^{2}+9 \lambda r+6 \lambda^{2}} \equiv x_{5}$, with the only binding inequality being the last one.

Follow the same logic for an equilibrium with bribing, where $\phi_{2}=0, w_{H}^{1}=p_{L}$, and verify that the conditions cannot be satisfied when $g(\bar{w})>0$, so this is an equilibrium only when $g(\bar{w}) \leq 0, w^{*} \geq p_{L}, V_{00}<\min \left\{V_{01}, V_{10}\right\}$ and $g\left(w^{*}\right) \geq 0$. These translate into $x_{1} \leq p_{L} / p_{H} \leq x_{6}$ when $2 r \leq \lambda$ and $x_{4} \leq p_{L} / p_{H} \leq x_{6}$ when $2 r>\lambda$, where $x_{1}=\frac{\lambda(4 r+7 \lambda)}{4 r^{2}+6 r \lambda+7 \lambda^{2}}, x_{4}=\frac{2(r+\lambda)^{2}}{4 r^{2}+5 r \lambda+2 \lambda^{2}}$ and $x_{6}=\frac{2(r+2 \lambda)^{2}}{4 r^{2}+9 \lambda r+8 \lambda^{2}}$.

Notice that $x_{6}>x_{5}$, so in the interval between them there is both an equilibrium with $\phi_{2}=0$ and $\phi_{2}=1$.

Identical procedures allow one to conclude that $\phi_{2}=0, w_{H}^{1}=\widetilde{w}$ in equilibrium only if $x_{0} \leq p_{L} / p_{H} \leq x_{3}$, where $x_{0} \equiv \frac{\lambda(r+\lambda)}{\left(2 \lambda r+\lambda^{2}+2 r^{2}\right)}$ and $x_{3} \equiv \frac{\lambda(3 r+4 \lambda)}{2\left(r^{2}+2 \lambda r+2 \lambda^{2}\right)}$, and by the same token that $\phi_{2}=0, w_{H}^{1}=w^{*}$ in equilibrium in two cases: one for $g(\bar{w})<0$ which exists only if $x_{2}<p_{L} / p_{H}<x_{4}$, which only can happen if $2 r>\lambda$ and where $x_{2} \equiv \frac{3 \lambda(r+\lambda)}{2 r^{2}+4 \lambda r+3 \lambda^{2}}$; another for $\bar{w}>p_{L}$, which happens to exist whenever $p_{L} / p_{H}<x_{0}$.

Notice that $x_{1}$ and $x_{2}$ are both smaller than $x_{3}$ in the relevant intervals, so there are regions where multiple equilibria with $\phi_{2}=0$ exist.

Figures 1 and 2 below illustrate the proposition. 


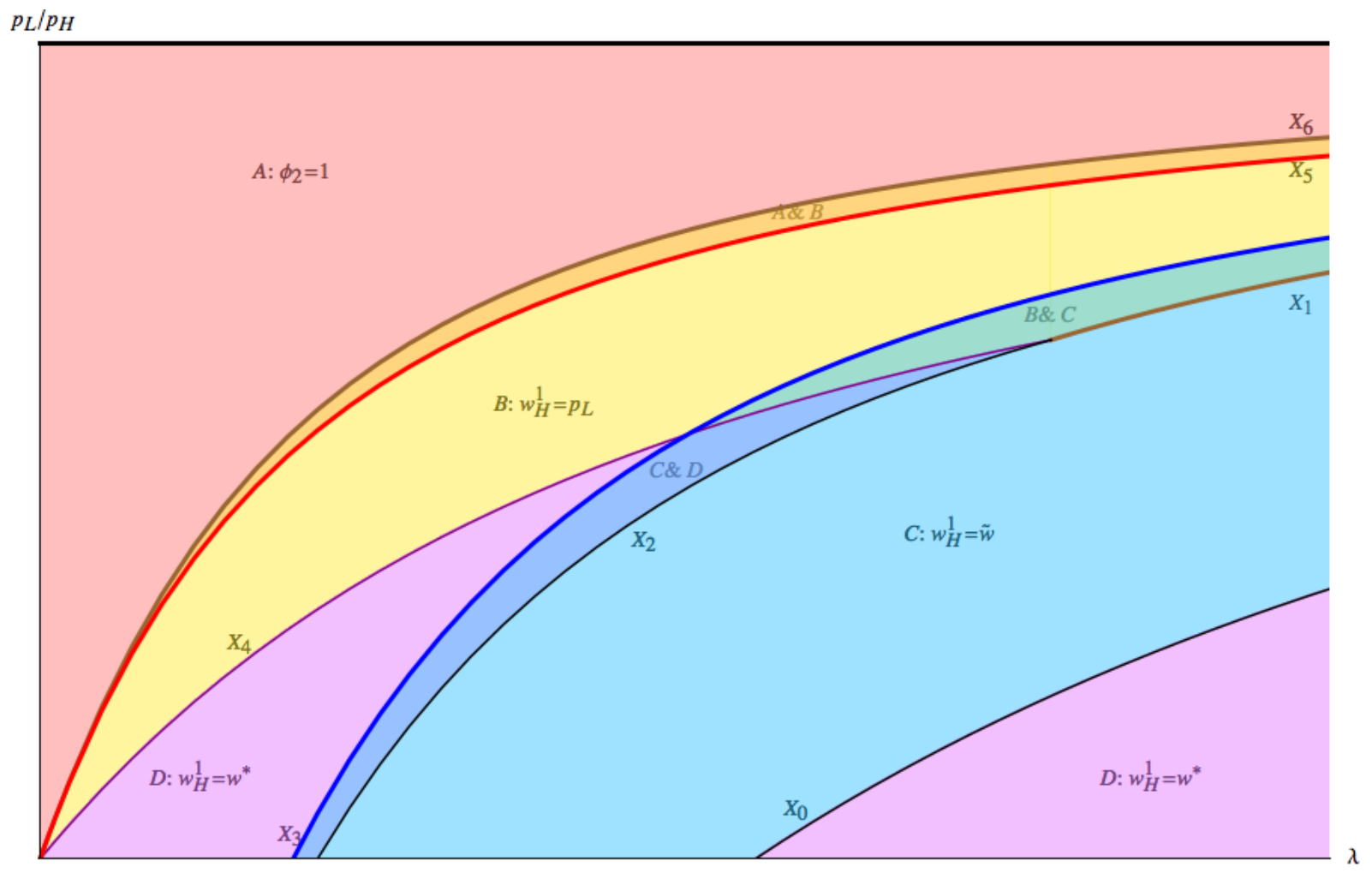

Equilibrium regions in $p_{L} / p_{H}, \lambda$ space

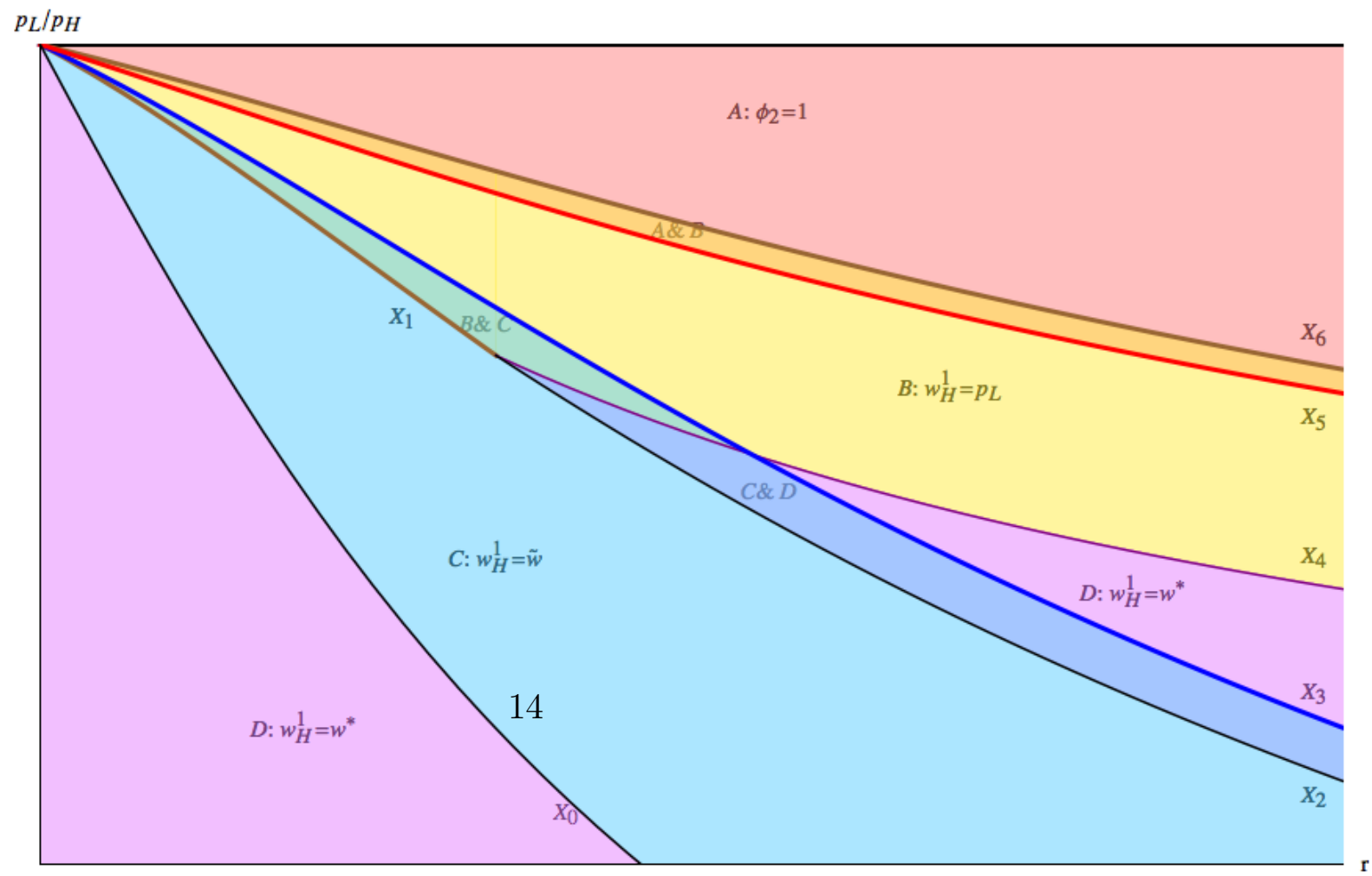


Intuitively, the proposition tells us that in equilibrium bribing will not be profitable (its too expensive) when $p_{H}$ and $p_{L}$ are very similar, and it will not be necessary (spouse $H$ gets very well paid anyway) when $p_{H}$ and $p_{L}$ are very different. Intermediate levels of $p_{L} / p_{H}$ render bribing profitable.

Furthermore, these areas overlap, so we have couples for whom both $\phi_{2}=0$ and $\phi_{2}=1$ correspond to equilibrium search behavior, other couples for which there are equilibria with and without bribing, and others for which two different non-bribing wages may emerge.

The graphs also illustrate the possibility of multiple equilibria. The orange region labelled $A \& B$ implies there are couples $p_{H}, p_{L}$ where, given the expectation that the firm would bribe, it is worthwhile for the firm to do so, and if there exists the opposite expectation it is also self-fulfilling. In these cases, the worker is strictly better off in the equilibrium with the bribe. Similarly, in the green region labelled $B \& C$, if agents expect the firm to bribe it is rational for them to do so, and if they expect to be paid an even higher wage that makes bribing unaffordable, the stronger bargaining position associated with that expectation makes it also an equilibrium. Finally, the blue region labelled $C \& D$ involves two non-bribing equilibrium levels for $w_{H}^{1}$; the difference between the two is in the expectation about what would happen, off the equilibrium path, in the event of a rejection and second offer in the bargaining game. This is specified in the following:

Corollary 1 For some parameter values, there are $p_{L}, p_{H}$ combinations for which multiple types of allocations can be equilibrium. In particular, for a certain constant $\Gamma$ :

- For couples that satisfy $x_{5}<\frac{p_{L}}{p_{H}}<x_{6}$ is satisfied, equilibrium may entail an outcome of type $A$ or of type $B$.

- For couples that satisfy $x_{1}<\frac{p_{L}}{p_{H}}<x_{3}$ (given $\lambda>2 r$ ), and for couples that satisfy $x_{4}<\frac{p_{L}}{p_{H}}<x_{3}$ (given $\Gamma r<\lambda<2 r$ ), equilibrium may entail an outcome of type $B$ or of type $C$.

- For couples that satisfy $x_{2}<\frac{p_{L}}{p_{H}}<x_{4}$ (given $\Gamma r<\lambda<2 r$ ), and for couples that satisfy $x_{2}<\frac{p_{L}}{p_{H}}<x_{3}$ (given $\lambda<\Gamma r$ ), equilibrium may entail an outcome of type $C$ or of type $D$.

Proof. It is easy to show that $x_{5}<x_{6}$ and $x_{1}<x_{3}$ and $x_{2}<x_{3}$. Further $x_{1}>x_{4}, x_{2}$ if $\lambda>2 r ; x_{2}<x_{4}$ if $\lambda<2 r ; x_{4}<x_{3}$ if $\Gamma r<\lambda<2 r$ and $x_{3}<x_{4}$ 
if $\lambda<\Gamma r .^{6}$

The reason for the multiple equilibria is quite intuitive: when firms bribe some workers in equilibrium, this increases the worker's bargaining position vis-a-vis an individual firm, making the bribe required lower relative to the otherwise agreed wage, and thus more likely to be optimal.

\section{Discussion}

Notice, for Type A couples (bribing does not take place and partners always keep searching until the first one to find a job is the one who stays at home), we have inefficient outcomes in about half of them: we will see the more productive spouse staying at home and the least productive working in the market. This represents a loss because both are equally good at home production, but not in the market. The loss, on the other hand, is not very big because the difference in productivities is small.

This inefficiency arises in part because we have chosen to make assumptions (namely, $\alpha=1$ ) that emphasize the complementarity between home work and market work. If one allowed some complementarity between the market work of the two spouses instead (for instance, if flow payoff, as a function of $p_{H}$ and $p_{L}$, was homogenous of a degree larger than one) then the outcome would be more compatible with optimality. But by making assumptions that imply that it is always optimal for one spouse to stay at home, we shut down this possibility. But the underlying message will still carry some truth given some degree of complementarity between home and market work $^{7}$ : that if one person staying at home is a common enough optimal move across the whole space of the marriages observed in equilibrium, then welfare would increase if one could swap $L$ in a very productive couple with $H$ in a very unproductive one. In all other cases, it is the $L$ type who will stay at home, and that is efficient.

Our model yields a source of wage distribution for equal workers not studied before : wages for equally productive workers may differ because

\footnotetext{
${ }^{6}$ Note that as $\lambda \Rightarrow \infty$, we have $x_{0}=\ldots x_{6}=1$, and only Type $\mathrm{C}$ equilibrium exists. This is efficient given only one of the partners will work at any given time: While unemployed, both find a job at the same rate. If the job is found by the $L$ first, she works only until $H$ finds a job. If the job is found first by $H$, she works for ever.

${ }^{7}$ As long as the very general conditions for an assortative equilibrium hold.
} 
they are married to partners of different productivity and/or because the order in which partners found jobs was different (since this has an impact on bargaining positions). The existence of multiple equilibrium adds a third source of possible heterogeneity. For the same reasons, our model also results in heterogeneity in search behavior in addition to wage heterogeneity.

\subsection{Implications for and of a marriage market}

Consider an agent of productivity $p_{i}$ married to an agent of productivity $p_{j} \leq p_{i}$. Then:

i) The discounted value upon entering the economy, $V_{00}$ depends on $p_{i}$ in addition to $p_{j}$. This follows immediately from the analysis above. Hence, we use $V_{00}\left(p_{i}, p_{j}\right)$ to highlight this dependence.

ii) $V_{00}\left(p_{i}, p_{j}\right)$ is not monotonic on $p_{j}$. Assume for a moment that in the region of multiple equilibria between $A$ and $B$, Equilibrium $B$ prevails. It can be shown that, for very small $\varepsilon, V_{00}^{B}\left(p_{i}, p_{i} x_{5}-\varepsilon\right)>V_{00}^{A}\left(p_{i}, p_{i} x_{5}\right)$ : For $p_{j}=p_{i} x_{5}-\varepsilon$, the couple is a Type $B$ couple where the $p_{i}$ spouse will be bribed by the employer if he finds a job first. As $p_{j}$ increases marginally to $p_{j}=p_{i} x_{5}$ there is a discrete loss in utility since the couple is now a Type $A$ marriage where the $p_{i}$ spouse will not be bribed. As a result, the $p_{i}$ spouse prefers marriage to a $p_{j}=p_{i} x_{5}-\varepsilon$ over $p_{j}=p_{i} x_{5}$.

iii) Not all agents rank potential partners in the same order. Following from the discussion in $i i$ ) above, for different $p_{i}$, the value $p_{j}=p_{i} x_{5}$ at which $V_{00}\left(p_{i}, p_{j}\right)$ drops discretely (as it changes from $V_{00}^{B}$ to $\left.V_{00}^{A}\right)$ is different.

Consider for a moment a stage previous to our labor market: Agents are born single and enter a marriage market, where they can search (at a minimal but positive search cost $\xi$ ) and encounter potential romantic interests. For two people to be able to marry they require to be compatible, which is a binary and reciprocal characteristic: two people are either compatible or they are not, without degrees of compatibility or uncorresponded feelings. The matching process delivers a Poisson arrival rate $\mu$ of compatible spouses. If two agents that meet find each other acceptable, they marry and enter the labor market studied above. When a couple marries, two clones enter the marriage market.

Although the equilibrium is of course impossible to characterize lacking formal analysis, some general observations can be made. 
It is easy to show that $V_{00}^{A}\left(p_{i}, p_{i}\right) \geq V_{00}^{B}\left(p_{i}, x_{5} p_{i}\right)$ if $\lambda$ is lower than or equal to a certain constant $\tilde{\lambda}$. In this case, the preferred match for the $p_{i}$ is $p_{j}=p_{i}$. Hence:

a) For a sufficiently high $\mu$, all couples formed will be very homogenous as people only marry those compatible partners with very similar productivities to their own, and $p_{L} / p_{H} \rightarrow 1$. All existing couples will be of Type $A$.

b) For lower arrival rates, results are not so straightforward as results i) - iii) above start to matter more in equilibrium. Nevertheless, there will be increased heterogeneity among partners, and thus among couples.

Hence, the magnitude of the arrival rate of spouses (determined by $\mu / r$ ) can affect the heterogeneity in terms of wages and search behavior of seemingly equal individuals and/or couples. When finding a spouse is easy enough (as $\mu / r$ gets large), all couples will be very homogenous. Alternatively, if $\mu / r$ is low, the equilibrium exhibits heterogenous couples. We will observe a dispersion of wages and search behavior across (seemingly equal individuals), as well as a dispersion of combinations of wages and search behavior across (seemingly equal) couples.

This introduces an additional source of inefficiency when the arrival rate of spouses is high: very productive individuals marry each other, only to have half of them staying at home, while very unproductive individuals also marry each other, to have half of them in the market. If the matching was not assortative, and instead couples married agents with very different productivities, one could have most of the highly productive individuals working and viceversa, with a higher average value across society. The optimum would be for each person in the more productive half of population to marry somebody from the least productive half, with only the former working in the long run, and only the latter staying at home. With high $\mu$, the equilibrium outcome is the opposite.

For $\lambda>\tilde{\lambda}$, then $V_{00}^{A}\left(p_{j}, p_{j}\right)<V_{00}^{B}\left(p_{j}, x_{5} p_{j}\right)$. In this case, the preferred match for the $p_{i}$ is $p_{j}=p_{i} x_{5}-\varepsilon$. Hence:

a) When $\mu / r$ is high it is likely that people of sufficiently equal productivity do not marry (if anything because more productive of the two is less likely to accept), and all marriages will be Type $B$. This is efficient in the sense that the low productivity worker will always end up engaged in home production. 
b) For lower rates we should see people with equal productivity start accepting each other, giving rise to an additional type of marriages (Type $A$ ). Hence, there will be some market inefficiencies, those related to type $A$ marriages. Further, this would enhance the heterogeneity in wages and search behavior.

c) As the arrival rate keeps decreasing, we should see the other types of marriages $(C$ and $D)$ starting to form.

\section{Conclusion}

We have developed a search model of the labor market where couples jointly decide the labor supply and home production of each partner. We find that the equilibrium involves different job search strategies for different couples and that, often, married agents stay at home. This is true even for the more productive spouse within the household, or somebody who has relatively high productivity among the population. Couples with similar productivities to each other tend to choose strategies where both spouses behave symmetrically, while asymmetric couples tend to have asymmetric strategies.

We find that when couples are asymmetric, but not too much, firms may find it optimal to unilaterally increase an employee's wage to induce the partner to abandon the labor market in favor of home production, therefore ensuring the employee will never quit. This generates multiple equilibria in terms of wages and search behavior. The multiple equilibria results from the feedback between a unilateral wage increase by the firm and the effects of this on a worker's bargaining position: if firms follow this strategy in equilibrium, this increases the worker's bargaining position vis-a-vis an individual firm, making the bribe required lower relative to the otherwise agreed wage, and thus more likely to be optimal.

Since search strategies of individuals depend on the relative productivities in a couple, and wages are affected by the labor market status of the partner, it is also true that wages will depend on the labor market history of the couple. Hence, our model provides an additional explanation for wage heterogeneity for identical workers. This extends also to identical couples (given different labor market histories). Such heterogeneity applies not only to wages but also to search strategies.

We find that, unambiguously, agents get better wage offers when their 
spouses are working and this offer increases with the spouse's wage, along the lines of Korenman and Newmark (1991).

Our modelling of the labor market has interesting implications for class formation as in Burdett and Coles (1997). Our results imply that, for newly born couples, their assumptions do not apply. In our model, the value of a marriage for individuals in newly born couples depends on the individual's own productivity in addition to the partner's productivity, and this value is not monotonic on the partner's productivity. As a result, different agents differ on how they rank any two potential spouses, which is also at odds with Burdett and Coles (1997).

When we do consider the possibility of marriage formation in the light of the above, we find our model tends to reconcile the results in Schwartz and Mare (2005) when the job arrival rate is low. The implications about income inequality do not necessarily follow. When the two spouses in the couple behave symmetrically in equilibrium, in about half the households at any given time the less productive spouse is in the market and the more productive one stays at home. This means the income distribution among households may or may not be more unequal than the productivity distribution among individuals. Thus, the results in Cancian et.al (1993) are also consistent with our theoretical results.

\section{References}

\section{References}

[1] Bonilla, R., Burdett, K. (2010). On-the-Job search and labor market equilibrium. The B.E. Journal of Macroeconomics 10(1)

[2] Bonilla, R., Kiraly, F. (2013). Marriage wage premium in a search equilibrium. Labour Economics 24, 107-115.

[3] Bonilla, R., Kiraly, F.,Wildman, J. (2015). Beauty Premium and Marriage Premium in Search Equilibrium: Theory and Empirical Test. CESifo Working Paper 5242.

[4] Burdett, K., Coles, M. (1997). Marriage and class. The Quarterly Journal of Economics 112(1), 141-168. 
[5] Cancian, M., Dazinger, S., Gottschalk, P. (1993). Working wives and family income inequality among married couples. In S. Dazinger and P. Gottschalk (Eds), Uneven tides: rising inequality in America (pp. 195-221). Russell Sage Foundation.

[6] Grossbard, S. (2015). The Marriage Motive: A Price Theory of Marriage. How Marriage Markets Affect Employment, Consumption and Savings. Springer.

[7] Jacobsen, J., Rayack, W.(1996). Do men whose wives work really earn less? American Economic Review 86(2), 268-273.

[8] Jacquemet, N., Robin, J.M.(2013). Assortative matching and search with labor supply and home production. CeMMAP Working Paper CWP07/13.

[9] Schwartz, C. (2010). Earnings inequality and the changing association between spouse's earnings. American Journal of Sociology 115(5), 1524-1557.

[10] Schwartz, C., Mare, R. (2005). Trends in educational assortative marriage from 1940-2003. Demography 42(4), 621-646.

[11] Song, Y.: (2007). The Working Spouse penalty/premium and married women's labor supply. Review of Economics of the Household 5,279-304.

[12] Violante, G., Guler, B., Guvenen, F. (2012). Joint-Search Theory: New Opportunities and New Frictions. Journal of Monetary Economics, $\mathbf{5 9 ( 4 ) , 3 5 2 - 3 6 9 . ~}$ 